\title{
Refining the Short Social Dominance Orientation Scale (SSDO): A Validation in Seven European Countries
}

\author{
Julian Aichholzer ${ }^{1}$, Clemens M. Lechner ${ }^{2}$ \\ [1] Department of Government, University of Vienna, Vienna, Austria. [2] GESIS-Leibniz-Institute for the Social Sciences, Mannheim, Germany.
}

Journal of Social and Political Psychology, 2021, Vol. 9(2), 475-489, https://doi.org/10.5964/jspp.6919

Received: 2020-11-04 • Accepted: 2021-05-12 • Published (VoR): 2021-09-16

Handling Editor: Marta Miklikowska, Umeå University, Umeå, Sweden

Corresponding Author: Julian Aichholzer, Department of Government, University of Vienna, Kolingasse 14-16, 1090 Vienna, Austria. E-mail: julian.aichholzer@univie.ac.at

Supplementary Materials: Data, Materials [see Index of Supplementary Materials]

\begin{abstract}
People and societies differ in their tendency to justify inequalities and group hierarchies, a motivation that has been labelled social dominance orientation (SDO). In order to efficiently measure this motivational tendency, Pratto and colleagues (2013, https://doi.org/ 10.1177/1948550612473663) proposed the four-item Short Social Dominance Orientation (SSDO) scale. The present study comprehensively assesses the SSDO scale's psychometric properties in seven European countries (Austria, Czech Republic, Germany, France, Hungary, Italy, and Poland). Using large and diverse samples from these countries, we propose a measurement model to assess the scale's structural validity and we assess measurement invariance (MI), reliability, and convergent validity. Results suggest that the scale is sufficiently reliable, shows theoretically predictable and consistent correlations with external criteria across countries, it exhibits at least partial scalar and partial uniqueness MI across the seven countries and full MI across gender. These findings offer support for the psychometric quality of the SSDO scale and its usefulness for cross-national and multi-topic social surveys.
\end{abstract}

\section{Keywords}

social dominance orientation, cross-cultural, short scale, measurement invariance, social inequality

Modern societies face persistent forms of social inequalities or hierarchies between social groups, such as gender inequality, inequality of ethnic or religious minorities, and inequality between social "classes." Such inequality might reflect access to power, the distribution of relevant resources or different treatment of people in everyday life (see Sidanius \& Pratto, 1999).

Social scientific research has tried to understand how people and societies cope with such inequalities and how they try to overcome them-but also how inequality is legitimized in a given social context. A body of literature centers around people's motivations that ultimately seek to produce and reproduce systems of social inequality. This type of motivational tendency, labelled social dominance orientation (SDO; Pratto, Sidanius, Stallworth, \& Malle, 1994), is defined as an individual's motivational goal to accept and maintain social hierarchies (i.e., anti-egalitarianism). Other authors have labeled SDO a system-justifying ideology (Jost \& Hunyady, 2005). Furthermore, SDO is regarded to be a core ideological attitude dimension underlying the left-right/progressive-conservative cleavage (see Duckitt \& Sibley, 2010; Jost, Federico, \& Napier, 2009). Apart from inter-individual differences, a body of literature has also looked at how societies differ in their tendency to justify inequalities and group hierarchies (Fischer, Hanke, \& Sibley, 2012; Kunst, Fischer, Sidanius, \& Thomsen, 2017). That is, citizens' level of SDO might be driven by contextual conditions, such as social conflict. 
In a nutshell, SDO does not represent the perception of how society is (does inequality exist?) or perceptions of justice (is inequality fair?), but rather value-based judgements of how society ought to be. For those who score high in SDO, the answer to this question is that society should be hierarchically ordered, with some groups possessing significantly more power who dominate others.

In order to measure individual and societal differences in this motivational orientation, Pratto and colleagues (1994) presented the initial 16-item SDO scale. Later this scale was elaborated with regard to potential subdimensions, namely SDO-Egalitarianism and SDO-Dominance (the 16-item $\mathrm{SDO}_{7}$ scale and its eight-item short form $\mathrm{SDO}_{7(\mathrm{~s})}$; see Ho et al., 2015). To offer an even more parsimonious measure of SDO, Pratto et al. (2013) also developed a short and balanced-keyed four-item version, the short social dominance orientation (SSDO) scale, and translated it to several languages.

The SSDO scale-which is the focus of the present study-is a potentially very useful complement to the longer measures such as $\mathrm{SDO}_{7}$. Because it comprises only four items that can be answered in less than 30 seconds, the SSDO is particularly well-suited for economically assessing SDO in multi-topic population surveys, in which time and questionnaire space are often strictly limited. This would apply, for example, to many of the cross-national surveys such as the European Social Survey (ESS). However, thus far, the SSDO scale has not been thoroughly tested with regard to its structural validity (internal structure), measurement invariance (MI), reliability, and convergent validity across countries using heterogeneous population samples.

In the present study, we present a comprehensive and rigorous assessment of the SSDO scale's psychometric properties. Our aim is to cast further light on the structural validity, reliability, MI, and convergent validity. We, first, develop a more fully specified measurement model for the scale, which is intended to better capture the items' data generating process, and explore the fit of this model to the data. Based on this model, we assess the scale's reliability (internal consistency). Second, we engage in exploratory data analyses guided by the question as to whether SDO can be measured equivalently across countries/language. That is, we investigate the extent to which MI can be achieved across countries/languages. In addition to testing MI across countries, we investigate MI across gender within each country. Third, we test several predictions on convergent validity of the SSDO scale. A central tenet of SDO's motivational structure is a disregard of social group equality, opposition to protecting minorities, and a competitive worldview about group dominance. Accordingly, we hypothesized that SDO as measured with the SSDO scale should be positively related to attitudes indicating rejection of plurality, rejection of minority rights, approval of violence (e.g., Duckitt \& Sibley, 2010; Pratto et al., 1994), and right-wing ideological self-placement (e.g., Jost et al., 2009).

For this purpose, we use large and diverse quota samples from seven European countries representing six national languages. Large and diverse samples furthermore minimize the potential impact of sampling bias when assessing the scale's properties. In addition to existing translations of the SSDO scale, we added two new language versions, namely Hungarian and Czech.

We make use of unique data from a multi-topic project on democratic attitudes and historical perceptions in Europe which was conducted in seven countries in total' ${ }^{1}$ : Austria (AT), Czech Republic (CZ), Germany (DE), France (FR), Hungary (HU), Italy (IT), and Poland (PL). On the one hand, the sample of countries was selected based on their unique historical backgrounds to study citizens' attitudes on current political issues and historical events. Specifically, these are Western and Eastern European countries that have experienced fascist (in AT, DE, FR, IT) and communist (in CZ, HU, PL and East DE) regimes and occupation, respectively, and then adopted democracy and market economy in the midto late $20^{\text {th }}$ century. On the other hand, the countries were selected based on recent political developments, particularly the electoral successes of radical right-wing and populist parties in these countries (Rooduijn et al., 2019) as well as the proliferation of ethno-nationalist or xenophobic political rhetoric in these countries (see, e.g., Wodak, 2015). ${ }^{2}$ Due to their unique socio-political and historical background the notion of the ideological terms social equality or "left" and

\footnotetext{
1) For further information, see the following website: https://zeitgeschichte.univie.ac.at/forschung/drittmittelprojekte/abgeschlossene-projekte/abgeschlossene-projekte-detailansicht/\#c704043

2) In particular, the Freedom Party of Austria (FPÖ), the National Front/Rally (FN/RN) in France, the Alternative for Germany (AfD), Fidesz-Hungarian Civic Alliance, (FIDESZ), the (Northern) League (LN) in Italy, and Law and Justice (PiS) in Poland are classified as far right and populist, which all show increasing or consolidated vote shares during the last decade (see Rooduijn et al., 2019).
} 
"right" might differ across contexts, and so might their psychological antecedents (see, e.g., Thorisdottir, Jost, Liviatan, \& Shrout, 2007). In summarizing, we draw attention to the question whether SDO can be measured equivalently across the countries studied here, since valid and invariant measurement of SDO is a key prerequisite for substantive questions about individual and cross-national differences in SDO.

\section{Materials and Method}

\section{Samples and Data}

Respondents were sampled from the following seven countries: Austria (AT), Czech Republic (CZ), Germany (DE), France (FR), Hungary (HU), Italy (IT), and Poland (PL). The survey was administered by the polling firm Respondi by means of computer-assisted web interviews (CAWI), that is, drawing from online access panels, and conducted between November and December 2019. The sampling scheme used population quota based on Eurostat data for the following variables: gender (male/female), age ${ }^{3}$ in five groups (16/18-29, 30-39, 40-49, 50-59, and 60+ years), education in three groups (Eurostat: low [ISCED 0-2], medium [ISCED 3-4], and high [ISCED 5-8] education), and region (either NUTS-1 or NUTS-2 regions). Table 1 shows the composition of the samples in terms of key socio-demographic characteristics. We acknowledge, however, that the samples drawn from online access panels are more ethnically homogeneous than the total population (e.g., due to language barriers and self-selection), thus limiting conclusions that could be drawn for ethnic minorities.

\section{Table 1}

Sample Descriptions, by Country (in \%)

\begin{tabular}{|c|c|c|c|c|c|c|c|}
\hline \multirow[b]{2}{*}{ Socio-demographics } & \multicolumn{7}{|c|}{ Country } \\
\hline & AT & $\mathrm{CZ}$ & DE & FR & HU & IT & PL \\
\hline \multicolumn{8}{|l|}{ Gender } \\
\hline Female & 49.9 & 49.6 & 49.5 & 51.0 & 50.8 & 50.3 & 50.5 \\
\hline \multicolumn{8}{|l|}{ Age (groups) } \\
\hline 16/18-29 years & 24.1 & 19.1 & 20.6 & 21.3 & 20.6 & 18.2 & 20.9 \\
\hline $30-39$ years & 19.0 & 21.1 & 18.6 & 19.2 & 19.4 & 17.8 & 22.7 \\
\hline $40-49$ years & 19.8 & 22.9 & 19.1 & 20.4 & 22.9 & 23.2 & 19.4 \\
\hline $50-59$ years & 21.7 & 18.0 & 23.8 & 20.4 & 17.7 & 22.7 & 18.1 \\
\hline $60+$ years & 15.4 & 18.9 & 18.0 & 18.7 & 19.4 & 18.1 & 18.9 \\
\hline \multicolumn{8}{|l|}{ Education (see Eurostat) } \\
\hline Low (ISCED 0-2) & 16.3 & 8.8 & 16.0 & 21.5 & 17.2 & 39.5 & 10.6 \\
\hline Medium (ISCED 3-4) & 53.3 & 69.5 & 57.8 & 44.5 & 60.5 & 43.1 & 62.3 \\
\hline High (ISCED 5-8) & 30.4 & 21.7 & 26.2 & 34.1 & 22.3 & 17.4 & 27.1 \\
\hline Migrant background & 15.0 & 2.0 & 8.7 & 11.0 & 3.0 & 4.0 & 1.2 \\
\hline Other citizenship & 7.9 & 1.0 & 2.5 & 2.1 & 0.4 & 0.8 & 0.2 \\
\hline Sample size $(N)$ & 1,000 & 1,000 & 2,000 & 2,000 & 1,000 & 2,000 & 2,000 \\
\hline
\end{tabular}

Note. $\mathrm{AT}=$ Austria; $\mathrm{CZ}=$ Czech Republic; $\mathrm{DE}=$ Germany; FR = France; HU = Hungary; IT = Italy; PL = Poland. Migrant background = Def. migrated into present country or both parents born abroad.

Several a-priori measures were taken during survey administration in order to enhance data quality. First, a quality check was built into a battery of Likert-type attitude questions (nine items in total) at the beginning of the survey. Re-

3) In Austria the minimum age was 16 years, whereas in all other countries the minimum age was 18. 
spondents with zero variance in their responses to these nine questions (i.e., a straight-lining pattern) were immediately excluded from the survey. Second, a trap question was introduced in the middle of the questionnaire: "Please click 'Next' without selecting any of the response options." If respondents ignored the instruction and chose an option, they were immediately excluded from the survey. Finally, respondents showing extreme speeding relative to other respondents (relative to the sum of median response times per page) were dropped ex-post by the polling firm. The remaining sample constitutes the basis for the following analyses (see Table S1 in the Supplementary Materials for details on sample inclusion).

We handled missing values (see Table 2 for frequencies) with the full information maximum likelihood (FIML) algorithm, which makes use of all available information and yields unbiased estimates under the assumption that data are missing at random (MAR). Even if data are not MAR, FIML typically results in less biased estimates than listwise deletion (Enders \& Bandalos, 2001). In addition, for all data analyses post-stratification weighting was applied, which is based on the population distributions used for the sample quota and vote recall of party voted in the last national election as a politically relevant criterion.

\section{Measures and Translation}

The survey was designed as an online multi-topic social survey. That is, time and questionnaire space were restricted. For this reason, the study team decided to include a validated short scale of SDO with as few items as possible. To measure SDO, we used Pratto et al.'s (2013) English-language source version of the SSDO scale, which comprises two positively and two negatively keyed items. It should be noted however that using this broad-domain short scale comes at the price of not being able to distinguish specific facets of SDO, that is, SDO-Dominance and SDO-Egalitarianism (see Ho et al., 2015).

Unlike the original scale, we decided to add the term societal groups to each statement for comprehensibility of what we mean by groups (see the Table S2 in the Supplementary Materials for all translations):

1. "In setting priorities, we must consider all societal groups."

2. "We should not push for equality of societal groups." [emphasis in original]

3. "The equality of societal groups should be our goal."

4. "Superior societal groups should dominate inferior groups."

Respondents rated all items on a fully labeled 7 -point scale $(1=$ strongly agree to $7=$ strongly disagree $) .{ }^{4}$ We hence recoded items 2 and 4 such that higher numeric values indicate a stronger SDO for all items (and for the resulting scale score).

We slightly adapted the existing translations to capture the substantive meaning as closely as possible (see Table S2 in the Supplementary Materials for a comparison of translations). Finally, translations for the new Czech and Hungarian version were developed by two separate translators each. The final version was selected based on semantic proximity to the English source items.

In addition to the SDO scale, several other political attitude questions and socio-demographic characteristics were available in the survey (see the results section on convergent validity below). To investigate convergent validity of the SSDO scale, we used the following additional measures: "In [COUNTRY] there is too much regard for minorities" and "Democracy must take into account the interests of different groups," which measure (anti-)pluralist attitudes (e.g., Akkerman, Mudde, \& Zaslove, 2014). To measure rejection of religious minority rights, we used two items: "Muslims in [COUNTRY] should have the right to build mosques" and "Jews in [COUNTRY] should have the right to build synagogues" (see, e.g., Van der Noll, 2014). We measured approval of violence (against out-groups) with two items: "When strangers spread out among us, we might use force to show them who is 'master in the house" and "If you want to make your wishes to come true, you sometimes have to use force" (see the group-focused enmity project; Zick et al.,

4) Note that Pratto et al. (2013) used a 1-10 response scale with endpoints labeled. We applied the fully labeled 7-point scale now also used in the SDO 7 scale (Ho et al., 2015). This decision follows previous evidence suggesting that fully labeled 5- to 7-point response scales generally achieve the highest measurement quality (see, e.g., Menold \& Bogner, 2016). 
2008). All items were measured on a fully labeled 5-point agree-disagree response scale. Finally, we used the standard left-right ideological self-placement scale which ranges from $0=$ left to $10=$ right .

\section{Results}

We began by examining descriptive item statistics, which are shown in Table 2. As can be seen, all four items are somewhat skewed: Respondents tended to disapprove the positively keyed items (which indicate higher SDO) but accepted the negatively keyed items (which indicate lower SDO). This means that, in line with previous studies, rejection of group dominance and inclusion of groups was generally more "normative" (Pratto et al., 2013) in all seven countries.

Table 2

Descriptive Item Statistics, by Country

\begin{tabular}{|c|c|c|c|c|}
\hline Country & Item 1 & Item 2 & Item 3 & Item 4 \\
\hline \multicolumn{5}{|l|}{ AT } \\
\hline$M$ & 2.52 & 4.18 & 2.86 & 5.63 \\
\hline$S D$ & 1.30 & 1.72 & 1.48 & 1.35 \\
\hline Skewness & 0.63 & 0.03 & 0.47 & -0.78 \\
\hline$\%$ missing & $2.1 \%$ & $7.4 \%$ & $4.2 \%$ & $4.9 \%$ \\
\hline \multicolumn{5}{|l|}{$\mathrm{CZ}$} \\
\hline$M$ & 2.79 & 4.34 & 2.89 & 5.33 \\
\hline$S D$ & 1.44 & 1.78 & 1.57 & 1.61 \\
\hline Skewness & 0.60 & -0.11 & 0.50 & -0.75 \\
\hline$\%$ missing & $1.9 \%$ & $3.6 \%$ & $2.5 \%$ & $3.7 \%$ \\
\hline \multicolumn{5}{|l|}{$\mathrm{DE}$} \\
\hline$M$ & 2.57 & 4.28 & 2.91 & 5.59 \\
\hline$S D$ & 1.29 & 1.69 & 1.51 & 1.39 \\
\hline Skewness & 0.52 & -0.07 & 0.50 & -0.79 \\
\hline$\%$ missing & $2.7 \%$ & $7.5 \%$ & $4.5 \%$ & $4.5 \%$ \\
\hline \multicolumn{5}{|l|}{ FR } \\
\hline$M$ & 2.72 & 4.28 & 3.03 & 5.63 \\
\hline$S D$ & 1.32 & 1.60 & 1.39 & 1.44 \\
\hline Skewness & 0.63 & 0.03 & 0.41 & -0.71 \\
\hline$\%$ missing & $5.1 \%$ & $8.5 \%$ & $6.7 \%$ & $5.0 \%$ \\
\hline \multicolumn{5}{|l|}{ HU } \\
\hline$M$ & 2.32 & 4.50 & 2.55 & 5.54 \\
\hline$S D$ & 1.41 & 1.82 & 1.47 & 1.64 \\
\hline Skewness & 0.99 & -0.22 & 0.67 & -1.02 \\
\hline$\%$ missing & $2.6 \%$ & $4.6 \%$ & $3.4 \%$ & $3.9 \%$ \\
\hline \multicolumn{5}{|l|}{ IT } \\
\hline$M$ & 2.53 & 4.75 & 2.50 & 5.58 \\
\hline$S D$ & 1.38 & 1.80 & 1.48 & 1.66 \\
\hline Skewness & 0.86 & -0.33 & 0.88 & -0.98 \\
\hline$\%$ missing & $3.7 \%$ & $5.0 \%$ & $3.3 \%$ & $3.7 \%$ \\
\hline \multicolumn{5}{|l|}{ PL } \\
\hline$M$ & 2.13 & 4.74 & 2.43 & 5.25 \\
\hline$S D$ & 1.25 & 1.77 & 1.44 & 1.57 \\
\hline Skewness & 1.04 & -0.37 & 0.90 & -0.68 \\
\hline$\%$ missing & $1.3 \%$ & $4.5 \%$ & $1.8 \%$ & $2.5 \%$ \\
\hline
\end{tabular}

Note. $\mathrm{AT}=$ Austria; $\mathrm{CZ}=$ Czech Republic; $\mathrm{DE}=$ Germany; FR = France; $\mathrm{HU}=$ Hungary; $\mathrm{IT}$ = Italy; PL = Poland. Original item keying with scores ranging from $1=$ strongly agree to $7=$ strongly disagree. Post-stratification weights were applied. 
Few respondents used the "don't know" category. The item with the highest percentage of "don't know" (\% missing) responses was item 2 including the negation not (ranging from $3.6 \%$ missing in $\mathrm{CZ}$ to $8.5 \%$ in FR).

\section{Measurement Model}

Next, we investigated the fit of different measurement models using confirmatory factor analysis (CFA) in the Mplus software (Muthén \& Muthén, 1998-2011). For this purpose, we initially made use of the pooled sample comprising all countries. We used robust maximum likelihood (MLR) estimation in Mplus throughout the analyses, which is generally recommended in case of skewed or nonnormal continuous indicators (see Li, 2016, p. 937).

Because the SSDO is a balanced-keyed scale (i.e., comprises the same number of positively and negatively worded items), a random intercept factor that reflects individuals' acquiescence response style (ARS) can be included in the measurement model (hereafter: ARS factor method; see, e.g., Aichholzer, 2014; Billiet \& McClendon, 2000). This is necessary because ARS entails spurious correlations between the questionnaire items that are not otherwise captured by the substantive factor (i.e., SDO). If unaccounted for, ARS can seriously bias correlations and MI tests, especially in cross-cultural comparisons (Lechner, Partsch, Danner, \& Rammstedt, 2019). The existence of an ARS factor has however not been tested previously. In addition, we investigated the possibility of a common wording or method factor (M), because two of the items ( 2 and 3 ) refer to "equality of societal groups," thus clearly mapping the SDO-Egalitarianism subdimension (see Figure 1). ${ }^{5}$

We tested different measurement models in consecutive steps using the pooled sample, with each model including additional specifications and latent factors. For this purpose, we looked at goodness-of-fit indices (Jackson, Gillaspy, \& Purc-Stephenson, 2009). We used the cut-offs of CFI and TLI $>0.90$, RMSEA $<0.08$, and SRMR $<0.08$ as indicating an acceptable model fit, and CFI and TLI $\geq 0.95$, RMSEA $\leq 0.05$, and SRMR $\leq$ 0.05 as indicating a good model fit (see, e.g., Sellbom \& Tellegen, 2019), whereas lower sample-size adjusted Bayesian information criterion (aBIC) values indicate relatively better fit.

Table 3 shows the fit indices for the alternative models. First, it is important to mention that a single-factor CFA model for SDO (model A) showed poor model fit, suggesting that a simple unidimensional measurement model for the four items is inadequate. This is surprising, given that Pratto and colleagues (2013, p. 590) previously reported an adequate-to-good model fit for the simple 1 -factor model in their pooled sample. This discrepancy in findings might be due to small $(N<200)$ and more homogenous samples in the original study (slightly younger, mostly recruited in person), which tend to yield better fitting measurement models (see, e.g., Rammstedt, Goldberg, \& Borg, 2010).

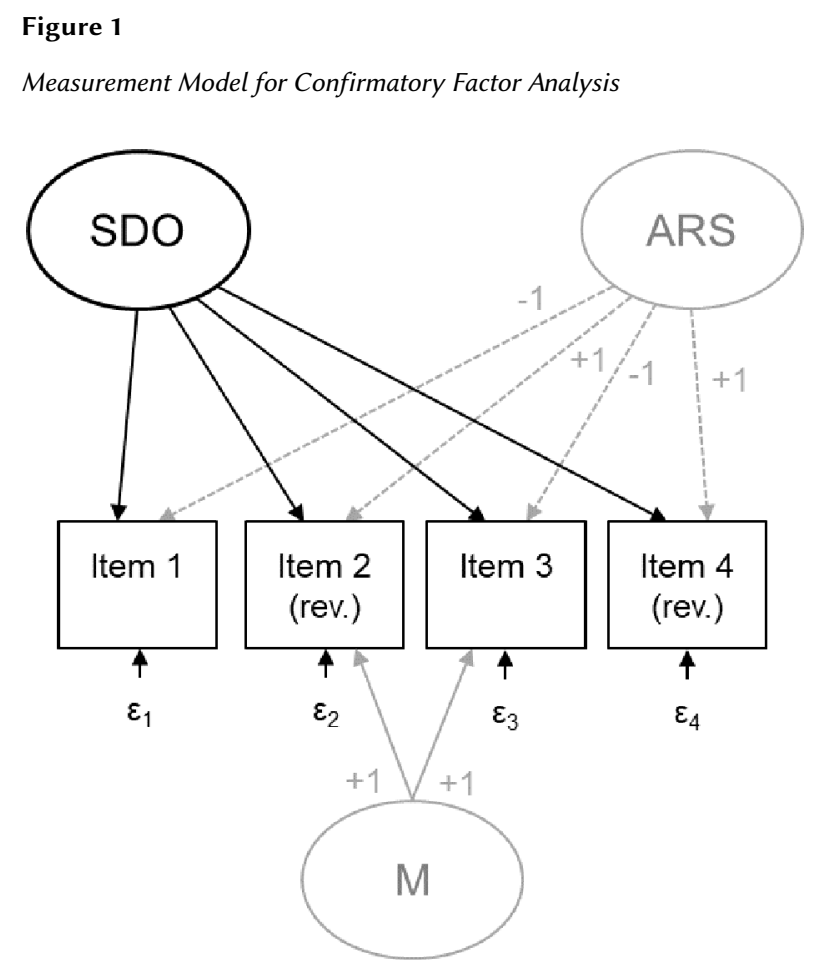

Note. $\mathrm{SDO}=$ Social dominance orientation; $\mathrm{ARS}=$ Acquiescence response style factor; $M=$ Method/wording factor; rev. = Negatively keyed items that were reverse coded (Original item keying with scores ranging from $1=$ strongly agree to 7 = strongly disagree).

One of the reasons is that more diverse samples comprise respondents with differential question comprehension, but also differential response tendencies, which impact the psychometric properties of the measurement instrument. As can be seen, including the ARS factor substantially increased model fit (see models C, D, and H). Because a model with an additional method/wording factor is just-identified ( $d f=0$; see model $\mathrm{G}$ ), we constrained the loadings of the items on

5) Note that this method factor is statistically identical to a residual covariance between the two items. 
the SDO factor to equality (i.e., we specified an essentially tau-equivalent model). Eventually, a measurement model that included the substantive SDO factor, plus an ARS and a method/wording factor fitted the data best (model H). In fact, this was the only model that showed satisfactory (good) fit according to all of the fit indices.

Table 3

Goodness-of-Fit Indices for Comparison of Different Measurement Models

\begin{tabular}{|c|c|c|c|c|c|c|c|c|c|}
\hline Model & $\begin{array}{l}\text { Model } \\
\text { specification }\end{array}$ & $\operatorname{MLR} \chi^{2}$ & $d f$ & $p$ & CFI & TLI & RMSEA & SRMR & aBIC \\
\hline A & 1 -factor & 674.79 & 2 & $<.01$ & 0.844 & 0.532 & 0.176 & 0.059 & 146,929 \\
\hline B & 1 -factor ${ }^{\mathrm{a}}$ & 1135.32 & 5 & $<.01$ & 0.738 & 0.686 & 0.145 & 0.102 & 147,737 \\
\hline $\mathrm{C}$ & 1 -factor + ARS & 151.34 & 1 & $<.01$ & 0.965 & 0.791 & 0.118 & 0.023 & 146,125 \\
\hline D & 1 -factor ${ }^{\mathrm{a}}+\mathrm{ARS}$ & 624.67 & 4 & $<.01$ & 0.856 & 0.784 & 0.120 & 0.069 & 146,798 \\
\hline $\mathrm{E}$ & 1-factor $+M$ & 989.40 & 1 & $<.01$ & 0.771 & -0.374 & 0.302 & 0.060 & 146,930 \\
\hline $\mathrm{F}$ & 1 -factor ${ }^{\mathrm{a}}+\mathrm{M}$ & 1094.75 & 4 & $<.01$ & 0.747 & 0.621 & 0.159 & 0.089 & 147,569 \\
\hline G & 1 -factor $+M+$ ARS & 0 & 0 & - & 1 & 1 & 0 & 0 & 145,895 \\
\hline $\mathrm{H}$ & 1 -factor ${ }^{\mathrm{a}}+\mathrm{M}+\mathrm{ARS}$ & 47.12 & 3 & $<.01$ & 0.990 & 0.980 & 0.037 & 0.024 & 145,942 \\
\hline
\end{tabular}

Note. Model fit for the pooled sample with $N=10,814$ using MLR/FIML estimation. Entries in boldface indicate an acceptable model fit according to criteria described in the text. ARS = Acquiescence response style factor; $M=$ Method/wording factor; CFI = Comparative Fit Index; TLI = Tucker-Lewis Index; RMSEA = Root Mean Squared Error of Approximation; SRMR = Standardized Root Mean Squared Residual; aBIC = Sample-size adjusted Bayesian information criterion.

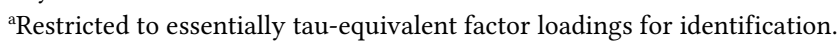

Table A1 in the Appendix reports the standardized factor loadings estimated from that best-fitting model (model $\mathrm{H}$ in Table 3). Standardized loadings of the four items on the substantive SDO factor ranged between .50 and .76 and are thus somewhat higher than the ones originally reported by Pratto et al. (standardized loadings between .43 and .60).

\section{Measurement Invariance}

The assessment of MI aims to establish whether a construct can be measured equivalently across groups, such as across countries or population subgroups (Putnick \& Bornstein, 2016). Using multiple-group CFA, the measurement model's parameters are constrained to equality in consecutive steps to assess whether certain levels of MI can be achieved across groups or countries (see Table 4): configural MI (same pattern of the overall factor loading structure) as a premise for the same baseline measurement model structure; metric MI (+ identical factor loadings across groups) as a premise for comparing construct correlations; scalar MI (+ identical item intercepts) as premise for comparing factor means; and uniqueness MI (+ identical item residuals) meaning that constructs are measured identically and factor variances can also be compared.

Table 4

Comparison of Goodness-of-Fit Indices for Testing Measurement Invariance Across Countries

\begin{tabular}{|c|c|c|c|c|c|c|c|c|}
\hline Model & Specification (Comparison) & $\operatorname{MLR} \chi^{2}$ & $d f$ & $p$ & CFI & RMSEA & SRMR & aBIC \\
\hline A & Configural & 73.39 & 21 & $<.01$ & 0.988 & 0.040 & 0.029 & 145,118 \\
\hline B & Metric & 73.39 & 21 & $<.01$ & 0.988 & 0.040 & 0.029 & 145,118 \\
\hline C & Full scalar (vs. B) & 252.86 & 27 & $<.01$ & 0.950 & 0.074 & 0.040 & 145,320 \\
\hline $\mathrm{D}$ & Partial scalar ${ }^{\text {a) }}$ (vs. B) & 89.84 & 26 & $<.01$ & 0.986 & 0.040 & 0.030 & 145,107 \\
\hline $\mathrm{E}$ & Full uniqueness ${ }^{\text {a) }}$ (vs. D) & 187.32 & 50 & $<.01$ & 0.970 & 0.042 & 0.056 & 145,123 \\
\hline $\mathrm{F}$ & Partial uniqueness ${ }^{\mathrm{a}, \mathrm{b})}$ (vs. D) & 139.17 & 49 & $<.01$ & 0.980 & 0.035 & 0.045 & 145,054 \\
\hline
\end{tabular}

Note. Entries in boldface indicate support of more restrictive MI step according to criteria proposed by Chen (2007). CFI = Comparative Fit Index; TLI = Tucker-Lewis Index; RMSEA = Root Mean Squared Error of Approximation; SRMR = Standardized Root Mean Squared Residual; aBIC = Sample-size adjusted Bayesian information criterion.

${ }^{a}$ Intercept of Item 4 set free in Poland. ${ }^{b}$ Residual variance of Item 1 set free in Poland. 
We relied on the recommendations by Chen (2007) for evaluating levels of MI, which are based on changes in goodness-of-fit indices for each MI level, rather than $\chi^{2}$-squared difference tests. Particularly in case of large samples, the $\chi^{2}$-squared difference test is likely not a suitable measure to detect MI, as shown by Rutkowski and Svetina (2014, p. 52). According to Chen (2007), metric non-invariance is indicated by a change of $\geq 0.010$ in CFI, supplemented by a change of $\geq 0.015$ in RMSEA or a change of $\geq 0.030$ in SRMR; scalar or uniqueness non-invariance is indicated by a change of $\geq 0.010$ in CFI, supplemented by a change of $\geq 0.015$ in RMSEA or a change of $\geq 0.010$ in SRMR. In addition, we compared the models' aBIC values, where lower values indicate a more favorable tradeoff between model fit and model complexity (parsimony).

For the purpose of testing MI, we used the fully specified model as shown in Figure 1 (or model $\mathrm{H}$ in Table 3), that is, tau-equivalent loadings on the target factor SDO and including the ARS and method/wording factor, which represents the baseline model for all countries. First of all, the model fit indices indicated that the configural model (model A in Table 4) generally fitted well in all countries. Although in general the configural and metric MI (see model B) models are nested, in this case the two models are identical, because of the equality restrictions across countries that we imposed on the loadings (recall that the model was an essentially tau-equivalent model). When comparing the full scalar MI model (model C) to the metric model, the fit indices suggested a minor misspecification. We only freed one parameter for achieving at least partial scalar MI (model D), namely the intercept of Item 4 in Poland. Descriptive results indicated that the item received relatively larger agreement (see Table 2). One reason might be that, unlike the original translation, two adjectives each were used to accurately translate the terms superior (=better, stronger) and inferior (=worse, weaker) in the Polish language. When comparing the full uniqueness MI model (model E) to a partial scalar MI model, we also found a minor misspecification. We thus resort to a partial uniqueness MI model, where the residual of Item 1 was set free in Poland in addition. The final partial uniqueness model (model F) fit the data very well, indicating that correlations, means, and variances of latent SDO scores can be meaningfully compared across all seven countries under study.

Supplemental analyses also investigated MI of SSDO items across gender within each of the countries (see Table S3 in the Supplementary Materials). The results suggested that SSDO scores can be meaningfully compared across men and women, generally supporting full uniqueness MI (see Table A2 for the mean scale scores by country). The results confirm previous findings that men generally have higher levels of SDO than women, whereas no relevant differences were found in the Czech Republic.

\section{Reliability}

We, next, provide reliability estimates for the composite score of the SSDO scale (i.e., the mean score of the four items) using Cronbach's $\alpha$ and composite reliability $\omega$ in Table 5. Means, standard deviations, and skewness of SSDO scale scores are also provided in Table $5 .^{6}$ The results corroborate that SSDO scale scores are generally skewed towards lower SDO levels (see also Figure A1 in the Appendix).

As can be seen in Table 5, the SSDO scale had good internal reliability across all of the countries investigated. Results were similar to Pratto et al. (2013) and Vargas-Salfate, Paez, Liu, Pratto, and Gil de Zúñiga (2018), who report an average reliability of $\alpha=.65$ (using a 10-point scale) and $\alpha=.64$ (using a 7-point scale), respectively. The composite reliability estimate $\omega$ is, in turn, based on the squared correlation between the latent SDO factor and a "phantom" composite score (see, e.g., Raykov \& Marcoulides, 2011), which is identical to $\alpha$ for tau-equivalent measures (i.e., equal factor loadings). However, given that positively correlated residuals exist, which are due to the method factor (M), Cronbach's $\alpha$ overestimates reliability. Hence, the deviation between $\alpha$ and $\omega$ generally increases, the larger the impact of the method factor specified here. In addition, controlling for ARS might have the opposite effect, because $\alpha$ underestimates reliability if any negatively correlated residuals are omitted, such as the attenuated correlation between positively and negatively keyed items.

6) We additionally provide mean scale scores across gender in Table A2 of the Appendix. 
Table 5

Reliability Coefficients and Descriptive Statistics of SSDO Composite Scale Scores, by Country

\begin{tabular}{|c|c|c|c|c|c|c|c|}
\hline \multirow[b]{2}{*}{ Statistic } & \multicolumn{7}{|c|}{ Country } \\
\hline & AT & $\mathrm{CZ}$ & $\mathrm{DE}$ & FR & HU & IT & PL \\
\hline Cronbach's $\alpha$ & .70 & .72 & .71 & .69 & .71 & .70 & .74 \\
\hline Reliability $\omega$ & .65 & .73 & .62 & .68 & .72 & .72 & .76 \\
\hline$M$ & 2.90 & 3.01 & 2.90 & 2.96 & 2.69 & 2.67 & 2.63 \\
\hline $95 \% \mathrm{CI}$ & {$[2.83,2.98]$} & {$[2.92,3.10]$} & {$[2.84,2.96]$} & {$[2.91,3.01]$} & {$[2.61,2.77]$} & {$[2.61,2.72]$} & {$[2.58,2.69]$} \\
\hline$S D$ & 1.07 & 1.19 & 1.08 & 1.04 & 1.16 & 1.16 & 1.13 \\
\hline Skewness & -.02 & .05 & -.02 & -.09 & .24 & .23 & .34 \\
\hline Sample size $(N)$ & 896 & 935 & 1,812 & 1,771 & 933 & 1,851 & 1,884 \\
\hline
\end{tabular}

Note. $\mathrm{AT}=$ Austria; $\mathrm{CZ}$ = Czech Republic; $\mathrm{DE}=$ Germany; $\mathrm{FR}=$ France HU = Hungary; $\mathrm{IT}$ = Italy; $\mathrm{PL}$ = Poland.

Reliability coefficients $\omega$ are based on the measurement model presented in Figure 1. Scale scores represent mean scores of the four items and range from 1-7. Post-stratification weights were applied.

Furthermore, results in Table 5 show SSDO mean scores across countries, suggesting small country-level differences ranging from 2.63-3.01, $F=27.97, p<.001, \eta^{2}=.016$ (cf. Vargas-Salfate et al., 2018, for example, who report SSDO scores from 2.28-3.57 in a sample of 19 countries). According to the results, Austria, Germany, France, but also the Czech Republic showed somewhat higher SDO scores than Hungary, Italy, and Poland. Standardized effect sizes for the pairwise country differences in SDO ranged from Cohen's $d=0$ to 0.32 , indicating that the differences were moderate in size (Lovakov \& Agadullina, 2021).

\section{Convergent Validity}

We used three attitudinal dimensions, which represent the mean score of two indicators each, and respondents' left-right ideological self-placement as criteria for convergent validity of the SSDO scale (see Table 6). We chose to report correlations based on the manifest SSDO scale score because, in practice, most researchers in social science research prefer using manifest scale scores over latent-variable modeling. Note, however, that using manifest variables (the SSDO scale score) is likely to entail conservative estimates of the correlations because measurement error in the scale score attenuates these correlations. In addition, the manifest scale score ignores the precise measurement model specification we proposed. Specifically, whereas our latent measurement model separates the general factor from a wording factor $(\mathrm{M})$, an acquiescence factor (ARS), and random measurement error $(\varepsilon)$, these variance portions are all confounded in the manifest scale score. We therefore also report correlations with the primary latent SDO factor in Table 6 (in square brackets).

The results in Table 6 show relatively consistent correlational patterns across the seven countries, despite these countries' different socio-political contexts. SDO had robust positive correlations in all countries with opposition to pluralism, rejection of minority rights, and approval of violence. The strongest correlation was found with opposition to pluralism, yielding high to perfect correlations with the latent SDO factor (Table 6). In general, the correlation with left-right ideology was somewhat weaker, with even weaker correlations in the Eastern European countries. These results convey the notion that left-right ideology might still have a different meaning in different parts of Europe. In particular, these patterns support the notion that acceptance of inequality is only weakly or, in the case of the Czech Republic, not at all related to general left-right ideology in Eastern European countries (see Thorisdottir et al., 2007).

In general, the latent-variable correlations were larger due to the disattenuation (i.e., correction for measurement error). However, in case of the left-right scale they appeared to be equal or even smaller than the manifest correlations (see Table 6). In this case the attitudinal covariates were in part associated with the unique variance represented by the wording factor $\mathrm{M}$. That is, the two items on "equality of societal groups" could have unique associations with some covariates, that is, over and above the general SDO factor. This additional factor could hence be used to provide the researcher with additional information. 
Table 6

Correlation of Manifest SSDO Scale Scores and Latent SDO Variable With Related Attitudinal Variables (Convergent Validity), by Country

\begin{tabular}{|c|c|c|c|c|c|c|c|c|}
\hline \multirow[b]{2}{*}{ Correlate } & \multicolumn{7}{|c|}{ Country } & \multirow[b]{2}{*}{ Avg. } \\
\hline & AT & $\mathrm{CZ}$ & DE & FR & HU & IT & PL & \\
\hline Anti-pluralism & $\begin{array}{c}.53^{*} \\
{[1.00]^{\dagger}}\end{array}$ & $\begin{array}{c}.39^{*} \\
{\left[.75^{*}\right]}\end{array}$ & $\begin{array}{c}.51^{*} \\
{[1.00]^{\dagger}}\end{array}$ & $\begin{array}{c}.42^{*} \\
{\left[.91^{*}\right]}\end{array}$ & $\begin{array}{c}.47^{*} \\
{\left[.92^{*}\right]}\end{array}$ & $\begin{array}{c}.42^{*} \\
{[1.00]^{\dagger}}\end{array}$ & $\begin{array}{c}.41^{*} \\
{\left[.87^{*}\right]}\end{array}$ & $\begin{array}{r}.45 \\
1.00 \\
\end{array}$ \\
\hline Rejection of min. rights & $\begin{array}{c}.38^{*} \\
{\left[.53^{*}\right]}\end{array}$ & $\begin{array}{c}.26^{*} \\
{\left[.35^{*}\right]}\end{array}$ & $\begin{array}{c}.38^{*} \\
{\left[.57^{*}\right]}\end{array}$ & $\begin{array}{c}.23^{*} \\
{\left[.27^{*}\right]}\end{array}$ & $\begin{array}{c}.29^{*} \\
{\left[.39^{*}\right]}\end{array}$ & $\begin{array}{c}.37^{*} \\
{\left[.45^{*}\right]}\end{array}$ & $\begin{array}{c}.23^{*} \\
{\left[.28^{*}\right]}\end{array}$ & $\begin{array}{l}.31 \\
.41 \\
\end{array}$ \\
\hline Approval of violence & $\begin{array}{c}.44^{*} \\
{\left[.58^{*}\right]}\end{array}$ & $\begin{array}{c}.36^{*} \\
{\left[.51^{*}\right]}\end{array}$ & $\begin{array}{c}.35^{*} \\
{\left[.53^{*}\right]}\end{array}$ & $\begin{array}{c}.33^{*} \\
{\left[.47^{*}\right]}\end{array}$ & $\begin{array}{c}.39^{*} \\
{\left[.55^{*}\right]}\end{array}$ & $\begin{array}{c}.47^{*} \\
{\left[.60^{*}\right]}\end{array}$ & $\begin{array}{c}.29^{*} \\
{\left[.37^{*}\right]}\end{array}$ & $\begin{array}{l}.38 \\
.52 \\
\end{array}$ \\
\hline Left-right self-placement & $\begin{array}{c}.42^{*} \\
{\left[.45^{*}\right]}\end{array}$ & $\begin{array}{l}-.01 \\
{[.00]}\end{array}$ & $\begin{array}{c}.34^{*} \\
{\left[.37^{*}\right]}\end{array}$ & $\begin{array}{c}.32^{*} \\
{\left[.31^{*}\right]}\end{array}$ & $\begin{array}{c}.20^{*} \\
{\left[.22^{*}\right]}\end{array}$ & $\begin{array}{c}.38^{*} \\
{\left[.39^{*}\right]}\end{array}$ & $\begin{array}{c}.16^{*} \\
{\left[.15^{*}\right]}\end{array}$ & $\begin{array}{l}.27 \\
.28\end{array}$ \\
\hline
\end{tabular}

Note. $\mathrm{AT}=$ Austria; $\mathrm{CZ}$ = Czech Republic; $\mathrm{DE}=$ Germany; FR = France; $\mathrm{HU}$ = Hungary; IT = Italy; PL = Poland.

See text for variable descriptions. Entries show Pearson correlations between manifest variables, which is the composite score of the items, and correlations with latent SDO variable (in square brackets); ${ }^{\dagger}$ Estimations would yield latent variable correlations $>1$, thus all correlations were restricted to unity. Average correlations based on Fisher's $z$-transformation. Post-stratification weights were applied.

${ }^{*} p<.05$.

\section{Discussion}

People differ in the extent to which they believe that society should be hierarchically ordered and that some groups should possess more power and influence than others do. In order to better understand and empirically measure this motivational orientation, Pratto and colleagues (Pratto et al., 1994; see also Sidanius \& Pratto, 1999) have coined the term SDO. Meanwhile, this variable has become one of the core constructs in understanding and predicting policy preferences, intergroup attitudes, and prejudice (see Duckitt \& Sibley, 2010; Ho et al., 2015; Jost et al., 2009; Jost \& Hunyady, 2005) and it has been studied from a cross-cultural perspective (Fischer et al., 2012; Kunst et al., 2017).

In order to measure this individual difference variable, short form instruments have been proposed, with some being more parsimonious and thus suitable for general population social and political surveys. The present study provided a comprehensive assessment of the psychometric properties of the four-item SSDO scale (Pratto et al., 2013). By using large and diverse samples from seven European countries, we were able to overcome the common limitation of using student and convenience samples that often limit the generalizability of scale assessments (see, e.g., Peterson \& Merunka, 2014; Rammstedt et al., 2010). In addition, we provided novel translations of the SSDO scale in Hungarian and Czech language that were not previously available.

\section{Summary}

First, we tested a series of refined latent measurement models. Our investigation of the structural validity of the SSDO scale suggested that a more elaborate measurement model, rather than a single-factor model, was needed to adequately represent the scale's structure. In particular, we proposed a model including respondents' ARS and a method factor for capturing semantic similarity (between items 2 and 3). This is important because a correct specification of the measurement model is needed in order to ensure that the means, variances and correlations of the SDO factor are unbiased. Furthermore, our results indicated that this wording factor could provide incremental substantive information about a SDO-Egalitarianism facet. Alternatively, the researcher can model the two items' commonality as residual covariance, thus neglecting their unique content.

Second, taken together, our results on the MI of the scale indicated that the measurement was indeed invariant across countries at levels that allow for the comparison of correlations, means, and variances of the latent SDO scores across countries. Only in the case of Poland, we failed to find support for full scalar and full uniqueness (i.e., strict) MI, but rather partial MI-still making comparisons of latent SDO scores possible. As mentioned above, the results for 
Poland may point towards problems with using additional adjectives to accurately translate item content (see Item 4). With regard to gender, our findings generally supported full uniqueness MI within each country.

Third, our findings support the relatively high internal reliability of composite scale scores $(\alpha=.69-.74$ and $\omega$ $=.62-.76)$, even though the scale is only a brief scale comprised of four items.

Fourth, convergent validity scores (i.e., correlations with external criteria) corroborate the notion that SDO is a significant and often strong predictor of peoples' attitudes toward democratic pluralism, minority rights, approval of violence, and ideological leanings. Furthermore, we found that the associations with other attitudes were highly consistent across the countries being investigated here.

When comparing composite scale scores across countries, we found that nations scoring highest on human development and democratic quality (Austria, Germany, France, but also the Czech Republic) exhibited somewhat higher SDO scores, whereas Hungary, Italy, and Poland scored lower on average (see Table 5). This finding disagrees with prior evidence suggesting that, on average, SDO may be higher in countries with more structural societal inequality, less democratic systems, and greater social instability, for instance (Fischer et al., 2012; Kunst et al., 2017). Economically speaking, the findings may nevertheless support a "system justification" account which maintains that advantaged social conditions make it more likely for people to support the existing social system (see also Vargas-Salfate et al., 2018). Another account would be that citizens in the high-SDO countries perceive their society as more competitive, i.e., as a struggle of groups for resources and power (Duckitt \& Sibley, 2010). This perception may as well be driven by increasing ethnic-cultural diversity (e.g., based on religion or non-European descent) and, thus, questions of group hegemony. That is, in certain countries matters of socio-cultural conflict may have brought preferences for majority group dominance to the fore. In fact, the radical right's rhetoric of exclusionary national identities has fueled such animosities, while at the same time such rhetoric has entered the center of every-day political discourse (Wodak, 2015).

\section{Limitations}

The present study also has limitations that need to be addressed. First, although (ultra-)short scales, such as the SSDO, retain the breadth of the construct, an obvious limitation is the loss of detailed information about subdimensions. That is, users may not be able to investigate facets of SDO, such as SDO-Egalitarianism and SDO-Dominance. In this case, readers might want to consult the eight-item short form of the $\mathrm{SDO}_{7}$ scale, for instance (Ho et al., 2015), which however lacks comprehensive MI testing.

Second, our findings regarding MI are, of course, restricted to the countries being investigated. Although we were able to leverage large- $N$ population samples, our selection was restricted to European countries, thus making it difficult to generalize to macro-level drivers of SDO beyond the case of Europe. The fact that country-level patterns, though not individual-level correlates, differ from prior research also calls for further replication and systematic cross-country comparisons using the SSDO scale. Future research might want to investigate the measurement properties further including other (non-European) countries, but also among specific social strata, for example. It has become more common to further investigate MI within populations, such as age groups or educational groups.

\section{Conclusion}

In sum, our study lends support to the utility of the SSDO scale as a measure of SDO. Thanks to its brevity, it lends itself particularly for multi-topic general population social surveys in which time and questionnaire space are restricted. Moreover, thanks to its MI across the countries/languages we investigated, the SSDO scale is well suited for application in cross-national surveys. 
Funding: This study is part of a joint research project headed by Oliver Rathkolb and has been funded by the University of Vienna, the Future Fund of the Republic of Austria, and the Fritz Bauer Institute. Work for this project was (partially) carried out at GESIS-Leibniz Institute for the Social Sciences and was financially supported by the GESIS research grant GG-2020-021.

Acknowledgments: We are especially thankful to the following people for assisting in the questionnaire translation: Liliana Nelska and Katharina Adamczyk (PL), Lucile Dreidemy and Tanja Schüberl (FR), Sylvia Kritzinger and Carolina Plescia (IT), Jiří Pešek and Veronika Dostálová (CZ), Murber Ibolya and Regina Fritz (HU). We also thank Felicia Pratto for providing comments on an earlier version of this paper.

Competing Interests: The authors have declared that no competing interests exist.

CRediT Authorship Contribution Statement: Julian Aichholzer: Conceptualization, Methodology, Formal analysis, Writing-original draft, Writingreview \& editing, Data curation, Project administration.

Clemens M. Lechner: Conceptualization, Methodology, Writing-original draft, Writing-review \& editing.

Data Availability: For this article, a dataset is freely available (Aichholzer \& Lechner, 2021).

\section{Supplementary Materials}

The Supplementary Materials contain the data and code required to replicate all analyses in this article as well as additional materials such as item translations (for access see Index of Supplementary Materials below).

\section{Index of Supplementary Materials}

Aichholzer, J., \& Lechner, C. M. (2021). Supplementary materials to "Refining the Short Social Dominance Orientation scale (SSDO): A validation in seven European countries" [Research data, materials, and code]. OSF. https://osf.io/g4jb8

\section{References}

Aichholzer, J. (2014). Random intercept EFA of personality scales. Journal of Research in Personality, 53, 1-4. https://doi.org/10.1016/j.jrp.2014.07.001

Akkerman, A., Mudde, C., \& Zaslove, A. (2014). How populist are the people? Measuring populist attitudes in voters. Comparative Political Studies, 47(9), 1324-1353. https://doi.org/10.1177/0010414013512600

Billiet, J. B., \& McClendon, M. J. (2000). Modeling acquiescence in measurement models for two balanced sets of items. Structural Equation Modeling, 7(4), 608-628. https://doi.org/10.1207/S15328007SEM0704_5

Chen, F. F. (2007). Sensitivity of goodness of fit indexes to lack of measurement invariance. Structural Equation Modeling, 14(3), 464-504. https://doi.org/10.1080/10705510701301834

Duckitt, J., \& Sibley, C. G. (2010). Personality, ideology, prejudice, and politics: A dual-process motivational model. fournal of Personality, 78(6), 1861-1894. https://doi.org/10.1111/j.1467-6494.2010.00672.x

Enders, C. K., \& Bandalos, D. L. (2001). The relative performance of full information maximum likelihood estimation for missing data in structural equation models. Structural Equation Modeling, 8(3), 430-457. https://doi.org/10.1207/S15328007SEM0803_5

Fischer, R., Hanke, K., \& Sibley, C. G. (2012). Cultural and institutional determinants of social dominance orientation: A cross-cultural meta-analysis of 27 societies. Political Psychology, 33(4), 437-467. https://doi.org/10.1111/j.1467-9221.2012.00884.x

Ho, A. K., Sidanius, J., Kteily, N., Sheehy-Skeffington, J., Pratto, F., Henkel, K. E., . . Stewart, A. L. (2015). The nature of social dominance orientation: Theorizing and measuring preferences for intergroup inequality using the new $\mathrm{SDO}_{7} \mathrm{scale}^{\text {. Fournal of }}$ Personality and Social Psychology, 109(6), 1003-1028. https://doi.org/10.1037/pspi0000033

Jackson, D. L., Gillaspy, J. A., Jr., \& Purc-Stephenson, R. (2009). Reporting practices in confirmatory factor analysis: An overview and some recommendations. Psychological Methods, 14(1), 6-23. https://doi.org/10.1037/a0014694 
Jost, J. T., Federico, C. M., \& Napier, J. L. (2009). Political ideology: Its structure, functions, and elective affinities. Annual Review of Psychology, 60, 307-337. https://doi.org/10.1146/annurev.psych.60.110707.163600

Jost, J. T., \& Hunyady, O. (2005). Antecedents and consequences of system justifying ideologies. Current Directions in Psychological Science, 14(5), 260-265. https://doi.org/10.1111/j.0963-7214.2005.00377.x

Kunst, J. R., Fischer, R., Sidanius, J., \& Thomsen, L. (2017). Preferences for group dominance track and mediate the effects of macrolevel social inequality and violence across societies. Proceedings of the National Academy of Sciences, 114(21), 5407-5412. https://doi.org/10.1073/pnas.1616572114

Lechner, C. M., Partsch, M. V., Danner, D., \& Rammstedt, B. (2019). Individual, situational, and cultural correlates of acquiescent responding: Towards a unified conceptual framework. British fournal of Mathematical and Statistical Psychology, 72(3), 426-446. https://doi.org/10.1111/bmsp.12164

Li, C. H. (2016). Confirmatory factor analysis with ordinal data: Comparing robust maximum likelihood and diagonally weighted least squares. Behavior Research Methods, 48(3), 936-949. https://doi.org/10.3758/s13428-015-0619-7

Lovakov, A., \& Agadullina, E. R. (2021). Empirically derived guidelines for effect size interpretation in social psychology. European fournal of Social Psychology. Advance online publication. https://doi.org/10.1002/ejsp.2752

Menold, N., \& Bogner, K. (2016). Design of rating scales in questionnaires. GESIS Survey Guidelines. Retrieved from https://www.gesis.org/fileadmin/upload/SDMwiki/MenoldBogner_Design_of_Rating_Scales_in_Questionnaires.pdf

Muthén, L. K., \& Muthén, B. O. (1998-2011). Mplus user's guide (6th ed.). Los Angeles, CA, USA: Muthén \& Muthén.

Peterson, R. A., \& Merunka, D. R. (2014). Convenience samples of college students and research reproducibility. Fournal of Business Research, 67(5), 1035-1041. https://doi.org/10.1016/j.jbusres.2013.08.010

Pratto, F., Çidam, A., Stewart, A. L., Zeineddine, F. B., Aranda, M., Aiello, A., . . Henkel, K. E. (2013). Social dominance in context and in individuals: Contextual moderation of robust effects of social dominance orientation in 15 languages and 20 countries. Social Psychological and Personality Science, 4(5), 587-599. https://doi.org/10.1177/1948550612473663

Pratto, F., Sidanius, J., Stallworth, L. M., \& Malle, B. F. (1994). Social dominance orientation: A personality variable predicting social and political attitudes. Fournal of Personality and Social Psychology, 67(4), 741-763. https://doi.org/10.1037/0022-3514.67.4.741

Putnick, D. L., \& Bornstein, M. H. (2016). Measurement invariance conventions and reporting: The state of the art and future directions for psychological research. Developmental Review, 41, 71-90. https://doi.org/10.1016/j.dr.2016.06.004

Rammstedt, B., Goldberg, L. R., \& Borg, I. (2010). The measurement equivalence of Big-Five factor markers for persons with different levels of education. fournal of Research in Personality, 44(1), 53-61. https://doi.org/10.1016/j.jrp.2009.10.005

Raykov, T., \& Marcoulides, G. A. (2011). Introduction to psychometric theory. New York, NY, USA: Routledge.

Rooduijn, M., Van Kessel, S., Froio, C., Pirro, A., De Lange, S., Halikiopoulou, D., ... Taggart, P. (2019). The populist: An overview of populist, far right, far left and eurosceptic parties in Europe. Retrieved from www.popu-list.org

Rutkowski, L., \& Svetina, D. (2014). Assessing the hypothesis of measurement invariance in the context of large-scale international surveys. Educational and Psychological Measurement, 74(1), 31-57. https://doi.org/10.1177/0013164413498257

Sellbom, M., \& Tellegen, A. (2019). Factor analysis in psychological assessment research: Common pitfalls and recommendations. Psychological Assessment, 31(12), 1428-1441. https://doi.org/10.1037/pas0000623

Sidanius, J., \& Pratto, F. (1999). Social dominance: An intergroup theory of social hierarchy and oppression. Cambridge: Cambridge University Press.

Thorisdottir, H., Jost, J. T., Liviatan, I., \& Shrout, P. E. (2007). Psychological needs and values underlying left-right political orientation: Cross-national evidence from Eastern and Western Europe. Public Opinion Quarterly, 71(2), 175-203. https://doi.org/10.1093/poq/nfm008

Van der Noll, J. (2014). Religious toleration of Muslims in the German public sphere. International fournal of Intercultural Relations, 38, 60-74. https://doi.org/10.1016/j.ijintrel.2013.01.001

Vargas-Salfate, S., Paez, D., Liu, J. H., Pratto, F., \& Gil de Zúñiga, H. (2018). A comparison of social dominance theory and system justification: The role of social status in 19 nations. Personality and Social Psychology Bulletin, 44(7), 1060-1076.

https://doi.org/10.1177/0146167218757455

Wodak, R. (2015). The politics of fear: What right-wing populist discourses mean. London, England: SAGE.

Zick, A., Wolf, C., Küpper, B., Davidov, E., Schmidt, P., \& Heitmeyer, W. (2008). The syndrome of group-focused enmity: The interrelation of prejudices tested with multiple cross-sectional and panel data. fournal of Social Issues, 64(2), 363-383. https://doi.org/10.1111/j.1540-4560.2008.00566.x 


\section{Appendix}

\section{Table A1}

Standardized Factor Loadings of the Four Items on the Substantive (SDO), Acquiescence (ARS), and Method (M) Factor, by Country

\begin{tabular}{|c|c|c|c|}
\hline Item \# & SDO & ARS & $\mathbf{M}$ \\
\hline \multicolumn{4}{|c|}{$\operatorname{AT}(N=988)$} \\
\hline 1 & .67 & .37 & \\
\hline 2 (rev.) & .50 & -.27 & .50 \\
\hline 3 & .59 & .32 & .59 \\
\hline 4 (rev.) & .63 & -.34 & \\
\hline \multicolumn{4}{|c|}{$\mathrm{CZ}(N=990)$} \\
\hline 1 & .69 & .37 & \\
\hline 2 (rev.) & .57 & -.31 & .38 \\
\hline 3 & .65 & .35 & .43 \\
\hline 4 (rev.) & .62 & -.34 & \\
\hline \multicolumn{4}{|c|}{$\mathrm{DE}(N=1,966)$} \\
\hline 1 & .67 & .32 & \\
\hline 2 (rev.) & .50 & -.24 & .56 \\
\hline 3 & .56 & .27 & .64 \\
\hline 4 (rev.) & .60 & -.29 & \\
\hline \multicolumn{4}{|c|}{$\mathrm{FR}(N=1,944)$} \\
\hline 1 & .66 & .35 & \\
\hline 2 (rev.) & .53 & -.28 & .40 \\
\hline 3 & .62 & .33 & .47 \\
\hline 4 (rev.) & .58 & -.31 & \\
\hline \multicolumn{4}{|c|}{ HU $(N=986)$} \\
\hline 1 & .70 & .36 & \\
\hline 2 (rev.) & .55 & -.28 & .34 \\
\hline 3 & .67 & .34 & .42 \\
\hline 4 (rev.) & .58 & -.29 & \\
\hline \multicolumn{4}{|c|}{ IT $(N=1,958)$} \\
\hline 1 & .69 & .40 & \\
\hline 2 (rev.) & .55 & -.32 & .36 \\
\hline 3 & .66 & .38 & .43 \\
\hline 4 (rev.) & .59 & -.34 & \\
\hline \multicolumn{4}{|c|}{ PL $(N=1,982)$} \\
\hline 1 & .76 & .41 & \\
\hline 2 (rev.) & .56 & -.31 & .32 \\
\hline 3 & .68 & .37 & .38 \\
\hline 4 (rev.) & .62 & -.34 & \\
\hline
\end{tabular}

Note. Estimates based on the measurement model presented in Figure 1 using FIML and MLR estimation. Post-stratification weights were applied. $\mathrm{SDO}=$ Social dominance orientation; $\mathrm{ARS}=$ Acquiescence response style factor; $M=$ Method/wording factor; rev. = Negatively keyed items that were reverse coded. 
Table A2

SSDO Composite Scale Scores (Mean Score), by Gender and Country

\begin{tabular}{lccccccc}
\hline Country & AT & CZ & DE & FR & HU & IT & PL \\
\hline Total sample & 2.90 & 3.01 & 2.90 & 2.96 & 2.69 & 2.67 & 2.63 \\
\hline Gender & & & & & & & \\
$\quad$ Male & 3.05 & 3.01 & 2.96 & 3.10 & 2.76 & 2.71 & 2.73 \\
$\quad$ Female & 2.75 & 3.01 & 2.84 & 2.82 & 2.62 & -.63 & -.08 \\
\hline diff. & $-.30^{*}$ & .00 & $-.12^{*}$ & $-.28^{*}$ & -.14 & $-.19^{*}$ \\
$95 \%$ CI & {$[-0.45,-0.16]$} & {$[-0.18,0.18]$} & {$[-0.23,-0.00]$} & {$[-0.38,-0.17]$} & {$[-0.31,0.02]$} & {$[-0.19,0.03]$} & {$[-0.30,-0.08]$} \\
Cohen's $d$ & 0.29 & 0.00 & 0.11 & 0.27 & 0.12 & 0.07 & 0.17 \\
$N$ & 896 & 935 & 1,812 & 1,771 & 933 & 1,851 & 1,884 \\
\hline
\end{tabular}

Note. $\mathrm{AT}=$ Austria; $\mathrm{CZ}$ = Czech Republic; $\mathrm{DE}=$ Germany; FR = France; $\mathrm{HU}=$ Hungary; $\mathrm{IT}$ = Italy; $\mathrm{PL}=$ Poland.

Scale scores represent mean scores of the four items and range from 1-7. Post-stratification weights were applied. Two-tailed significance level: ${ }^{*} p<.05$.

\section{Figure A1}

Frequency Distribution of SSDO Scales Scores, by Country
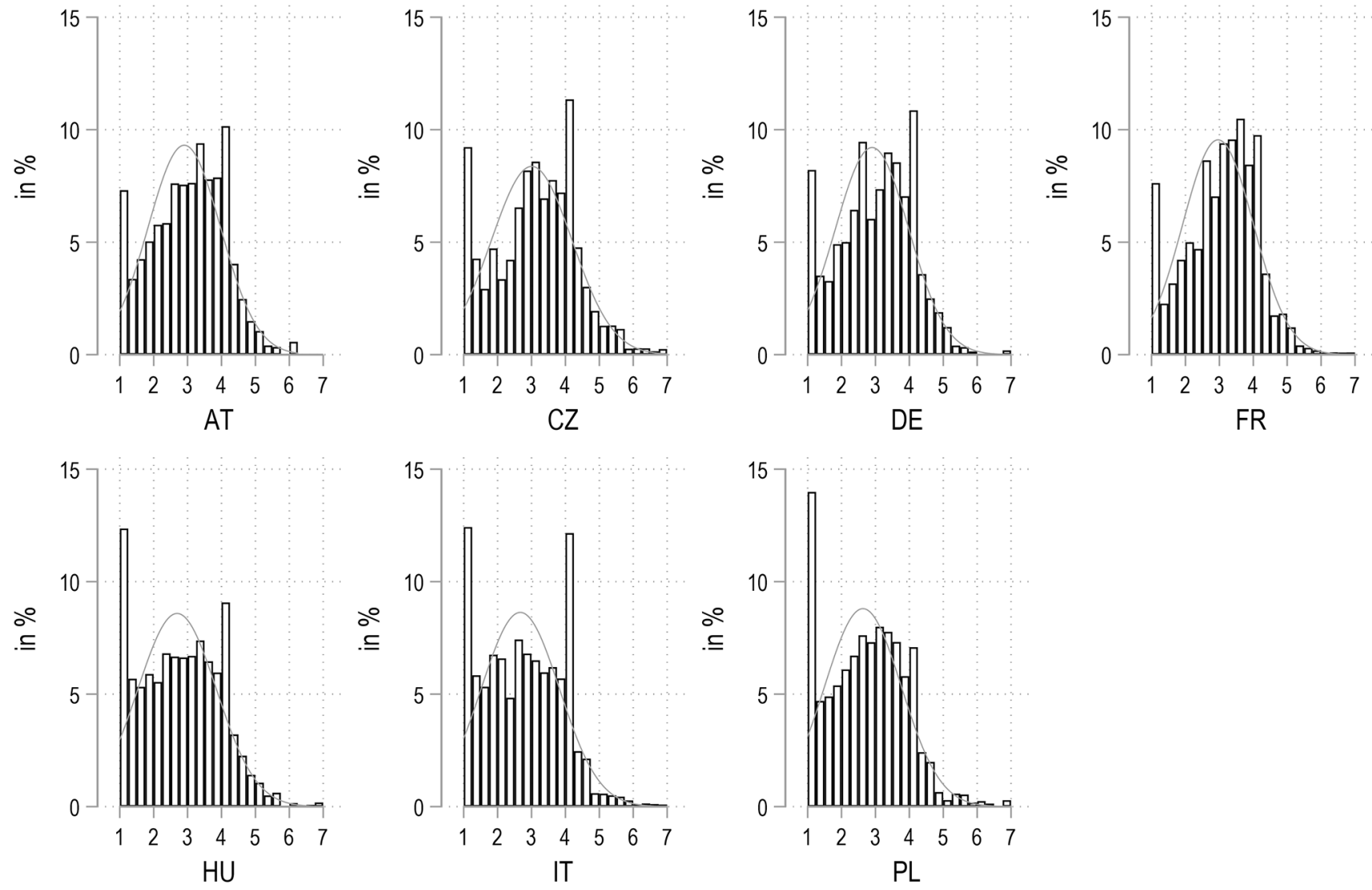

Note. Mean scores ranging from 1-7. Post-stratification weights were applied. 